\title{
A virtualidade como reencantamento da aprendizagem
}

\author{
"A imaginação inventa mais do que as \\ coisas e os dramas, ela inventa vida nova, \\ ela inventa o espírito novo, ela abre os \\ olhos a novos tipos de visão". \\ G. Bachelard.
}

\section{Introdução}

Vivenciamos a ultrapassagem de uma visão ingênua que delega à tecnologia um valor diferente que não o de auxiliar na formas de aprender e de agir dos seres humanos, pois já presenciamos um cenário de transformações potenciais na vida das pessoas conectadas pela interação. Minha contribuição nesse sentido será trazer minha experiếncia concreta no processo de utilização das tecnologias e, a partir da reflexão sobre a cartografia vivenciada num espaço multimeio, mostrar, como na práxis, pode emergir subjetividade/conhecimento através do uso da Internet. Cabe ressaltar que esse espaço relacional não foi projetado para ensinar, mas para desencadear novos modos de pensar e de inventar. Aanálise do caminho percorrido permite observar os movimentos, os desdobramentos, e principalmente, conforme Maturana (1999), que o conhecimento se dá na práxis do viver, e por isso precisa ser inserido no contexto da vida dos aprendizes.

Minha opção pelo método topológico

PALAVRAS-CHAVE

- Novas Tecnologias (New Technologies)

- Internet (Internet)

- Reencantamento (Reenchantment)

Dulci Boettcher

Professora da UNISC/RS deve-se à possibilidade de novas e inesperadas configurações, o pensamento se produzindo junto com o acontecimento, e nesse sentido, o modelo cibernético nos aponta as rupturas do modo tradicional de aprendizagem, tornandose necessária a escolha por uma metodologia diferente, não mais centrada no docente, mas que dê conta dessa totalidade que diz respeito às relações entre os seres humanos. Outra razão que justifica esta escolha deve-se às descobertas científicas no nosso século, principalmente a partir dos anos 50. Com a velocidade do surgimento dos saberes e a renovação dos mesmos, modificase a antiga relação com a competência dos sujeitos, antes substancial e territorial. Temos hoje, a possibilidade de disponibilizar ferramentas que orientem para $\mathrm{o}$ ato de aprender e, por incentivarem a autonomia na aquisição do conhecimento, mudam completamente o cotidiano da escola, dificultando, muitas vezes, a relação entre 
professores e alunos e, conseqüentemente, a aprendizagem.

Pela primeira vez dispomos de uma técnica que pode permitir de um modo verdadeiramente operacional e razoável uma gestão coletiva do coletivo, pois dispomos de um instrumento que permite ao indivíduo comunicar-se com o coletivo, que permite a grupos comunicarem-se entre si, possibilitando a comunicação transversal (Lévy, 1996,p.15).

2 Ecologia cognitiva: a importância da técnica na formação de novos agenciamentos

A interação entre o sujeito com instituições, outros sujeitos, máquina e natureza, denominada de ecologia cognitiva, tem suas bases nas relações do homem com o seu meio - seja no plano econômico, científico, artístico, político ou pedagógico. Para Lévy (1998), as faculdades de conhecimento trabalham com línguas, sistemas de signos e processos intelectuais fornecidos por uma cultura. Assim, a inteligência ou a cognição é fruto da coletividade e das tecnologias intelectuais.

A Internet, por possuir as características de redeentraemcenacomorecursoimportantepara a democratização do saber, interligando milhões de computadores, tornando-se o espaço de troca de informações e comunicação em geral, um verdadeiro instrumento de potencialização do conhecimento. Essas características, tais como autonomia, circularidade, recursividade, cooperação, etc, permitem um ambiente virtual de aprendizagem diferente, com professores e alunos trabalhando sem limitações de tempo ou barreiras geográficas, pois, segundo Lévy (1998, p.27),

Em nossas interações como as coisas, desenvolvemos competências. Por meio de nossas relações com os signos e com a informação adquirimos conhecimentos. Em relação com os outros, mediante iniciação e transmissão,fazemosvivero saber.(....)Toda a atividade, todo ato de comunicação, toda relação humana implica um aprendizado. Pelas competências e conhecimentos que envolvem, um percurso de vida pode alimentar um circuito de troca, alimentar uma sociabilidade de saber.
Entende-se, dessa maneira, que a informática é muito mais do que uma revolução nas formas e métodos de geração, armazenamento, processo e transmissão da informação. "Tudo que for capaz de produzir uma diferença em uma rede será considerado como um ator, e todo o ator definirá a si mesmo pela diferença que produz"(Lévy, 1999, p.136). O autor refere-se aos dispositivos técnicos, como atores na coletividade, bem como sua contribuição para a formação e estrutura das sociedades, pois a história nos mostra que ferramentas funcionam como dispositivos culturais, e isso poderá ocorrer da mesma forma em relação aos computadores na reorientação do sistema educativo.

No que se refere à aprendizagem, a técnica oportuniza ao aluno construir significações ampliando seu conhecimento. A entrada do computador na escola não é mais uma opção, mas uma realidade que poderá contribuir para formar culturas do conhecimento com coletivos pensantes, incluindo homens, coisas, instituições, sociedade e técnicas de comunicação, reestruturando modos de pensar.

Visto dessa maneira, as tecnologias são constitutivas de novos agenciamentos, e a Internet possui usos variados e ilimitados, não apenas como algo material, mas como um conjunto de possíveis, conforme ressalta Lévy (1999, p. 101):

As técnicas não determinam, elas condicionam. Abrem um largo leque de novas possibilidades das quais somente um pequeno número é selecionado ou percebido pelos atores sociais. Se as técnicas não fossem elas mesmas condensações da inteligência coletiva humana, poder-se-ia dizer que a técnica propõe e que os homens dispõem.

Mas somente a implementação da tecnologia não garante o conhecimento/ subjetividade. Atualmente, encontramos estudos e avanços com novas propostas e novas ferramentas que auxiliem na aprendizagem, através da utilização da tecnologia. Jean Piaget (1997), Pierre Lévy (1995, 1996, 1998, 1999), Seymour Papert (1994), Gregory Bateson (1999), H. Bergson (1998), Humberto Maturana $(1994,1997)$ Maturana e Francisco Varela (1990), entre outros, são exemplos importantes. Ativeme, porém, principalmente aos dois últimos 
autores, pois tratam a questão do conhecimento a partir de uma nova perspectiva.

3 Uma abordagem a partir da biologia...

Nós nem sempre aceitamos as perguntas que nos são formuladas, ainda quando dizemos que as aceitamos. Aceitar uma pergunta significa mergulhar-se na procura de sua resposta (Maturana, 1999).

É grande a responsabilidade que nos cabe, não apenas em relação à aprendizagem, mas em todos os aspectos da vida, pois conforme nos alerta Maturana (2001, p.181), podemos mescolher se queremos ser " homo sapiens sapiens, Homo sapiens amans, Homo sapiens agressans ou Homo sapiens arroggans", pois nossas emoções são responsáveis, por nossas escolhas.

A cognição, nessa perspectiva, só é possível na interaração, o que justifica a necessidade de ambientes que permitam autonomia, que contemplem a presença do amor e do respeito, para que possamos vivenciar e relacionar nossas sensações de corpo com os processos mentais, e deixá-lo aberto para a aprendizagem.

Humberto Maturana (1992), em sua teoria da Biologia do Conhecer, nos mostra que é preciso entender a vida como um processo de conhecimento e que o viver e o conhecer são inseparáveis. Não se trata, portanto, de adquirir conhecimento, já que este, como fenômeno biológico, ocorre no ser vivo o tempo todo, e sim, de um processo contínuo de transformação estrutural de um organismo com outro. Em outras palavras, "o conhecimento acontecerá, num domínio de interações de qualquer sistema dinâmico enquanto opera num acoplamento estrutural com suas circunstâncias".(Mpodozis e Matuana,1992).

A Internet possibilita um ambiente autônomo, pois serve de exemplo à criação de grupos de discussão, nos quais comunidades virtuais exploram as riquezas existentes na população, trocando questionamentos, criando uma memória coletiva, oriunda da interação das pessoas. A organização dos sistemas vivos é circular, auto-referencial e sua organização é uma organização fechada e, portanto autônoma. No ser vivo, há um processo de autoconstrução e autonomia, que, a partir de um sistema complexo, se articula com a rede, e, portanto, com a Internet. Como não há reprodução de uma realidade externa - não há representação - o meio externo só age como elemento perturbador que desencadeia mudanças. Por isso que dizemos que o modelo da vida é o modelo da rede, pois tudo acontece na interação, e o modelo rede está em todas as dimensões do humano, no sistema imunológico, nervoso, social, nos remetendo conceito de autopoise, cunhado por Maturana e Varela (1990, p. 25) "os seres vivos se caracterizam pelo fato de, literalmente, se produzirem continuamente a si mesmos, e assim, chamamos a organização que os define, de organização autopoiética".

\section{$4 \quad$ O contexto da experiência}

Para concretização de minha pesquisa e para construir um ambiente coerente com minhas opções teóricas, utilizei o laboratório de informática do Curso de Letras da Universidade de Santa Cruz do Sul, UNISC, e contei com a participação de um grupo de seis alunos de diferentes áreas, de idade entre 17 e 29 anos. Juntos, interagimos no ambiente multimeio, durante dois meses, duas vezes por semana, em busca de novas possibilidades de utilização da Internet para o ensino de língua inglesa, tendo em vista sua utilização como instrumento pedagógico dinâmico. O ambiente, portanto, tinha que ser de coerência com minhas crenças teóricas de que não se ensina, mas se vive o conhecimento, e, que o mesmo emerge na recorrência, na recursividade. Este se constituiu de alunos, computadores e de uma pesquisadora que, apesar de munida de várias hipóteses, não desejava interferir com conteúdos pré-determinados, como acontece na escola tradicional.

Eu pretendia, portanto, para desenvolvimento de minha pesquisa, um contexto onde fosse possível criar, inventar, pois se criamos problemas, abrimos novos caminhos, novos modos de experimentar a vida, a partir do desequilíbrio, da não-aceitação de conceitos hegemônicos. A Internet, nesse sentido, é uma ferramenta que possibilita um caminho fértil de invenção de problemas. Em Virginia Kastrup, (1999, p.183), encontrei Bergson (1988) que ressalta: "A técnica não é somente o terreno de objetos artificiais, mas potência de artificialização da cognição e de virtualização da inteligência." O que precisamos entender é que a técnica "não artificializa uma natureza dada, mas reverbera sobre a natureza da cognição, 
natureza em si mesma artificiosa e inventiva, que a vida virtual prepara"(Idem). Os autores sugerem, dessa forma, a possibilidade de pensar a cognição como híbrido de natureza e artifício.

O ambiente precisava ser acolhedor, e o laboratório prometia ser o espaço relacional de imanência onde o aluno, no conviver do cotidiano, transformasse e se transformasse no processo de construção e em congruência com o outro. Conhecimento é mais do que informação apenas, e a inseparabilidade do ser/ conhecer sugere que a cognição só é possível na interação, e por isso o ciberespaço foi pensado para oportunizou uma outra abordagem de conhecimento, cuja configuração fosse reflexo desse viver.

Busquei novos movimentos de construção da realidade, diferente dos modelos com conteúdos postos a priori. Estes foram emergindo durante a relação, num processo de negociação, numa interação mútua quando um é afetado, modificando todo o sistema. Procurei observar, dessa forma, como os alunos realizavam as operações, não quanto ao seu aspecto quantitativo, mas o qualitativo, avaliando principalmente, as transformações ocorridas na relação em termos de metacognição. O aprender sobre o aprender esteve presente o tempo todo, através de reflexões sobre as estratégias e de monitoramentos de desempenhos em certas tarefas.

Comalnternet,foipossívelcriarusosmúltiplos e diferenciados ao aprendizado e, durante a experiência, como na cartografia, estive atenta às mudanças, corrigi o curso quando necessário e, como orientadora, procurei acompanhar os meandros da produção do conhecimento. Nesse processo, os alunos se construírem autonomamente, utilizaram mecanismos de ação coletiva e consensual, e, a partir de temas e/ou problemas do cotidiano, utilizaram a Internet como amplo dispositivo para navegar, inventar. Mobilizados, os alunos abandonaram a tradicional postura de dependência para uma crescente autonomização/cooperação, no sentido autopoiético, uma vez que, ao se apropriaram do dispositivo como algo original, estavam aptos a construir outros dispositivos para disparar, autoconstruir como a homepage, a lista, o e.mail, entre outros.

5 Registros da experiência/ práticas concretas

Para que a interface fosse plenamente interativa, foi preciso trabalhar na virtualidade, o que possibilitou a ocorrência da problemática e viabilizou atualizações que desencadearam novos modos de pensar e de agir. Criou-se, assim, um novo mapa onde as "coisas" foram atualizadas. Em vez de utilizar receitas prontas, optei por buscar novos caminhos e soluções próprias. As ações que mostram o processo se deram, através da troca de informações, atualização e descoberta de melhores e mais eficazes modos de operacionalizar os recursos tecnológicos. Aaprendizagemnessa perspectiva, é ao mesmo tempo colaborativa e autônoma, e forma as bases para a habilidade dos alunos de engajar-se no processo de aprendizagem transformadora.

O novo paradigma educacional me inclui como observadora de processualidades e, através da cartografia, levando em conta a potencialidade do ambiente virtual do laboratório, procurei avaliar a participação dinâmica dos envolvidos na pesquisa.. Através da adoção da web como ambiente educacional, através de práticas concretas, observei a interação nesse processo de reflexão/ação. A ausência de hierarquia rompeu as amarras da seqüencialidade linear, e a liberação da dimensão do tempo permitiu o trabalho síncrono e assíncrono.

As atividades desempenhadas durante o laboratório eram bastante variadas. Os textos, todos em inglês, eram lidos pelos alunos diretamente na tela. A Internet, pela vasta quantidade de informações disponíveis, e a falta de uma organização sistemática dessas informações, criou uma atmosfera pela qual os alunos tornam-se conscientes das habilidades de leitura e tiveram seu interesse despertado pela mesma. Os alunos dividiram documentos, textos e idéias com professora e colegas, e se comunicaram rápida e facilmente, através de chats com falantes nativos ou outros aprendizes da língua-alvo em todo o mundo. A conexão com a grande rede, ao utilizar os chats, não assustou os alunos, ao contrário, participaram do bate papo de maneira descontraída, e isso, pode ser percebido logo após os primeiros momentos, ao darem respostas às perguntas que iam surgindo na tela.

O grupo possuía uma lista de discussão, e a consulta à mesma privilegiava os interesses específicos sobre temas referentes à cultura, sociedade e meio ambiente. Essa foi uma fonte riquíssima para o envolvimento dos alunos com 
a língua inglesa, com link ao dicionário de Inglês, para facilitar a busca e o entendimento. No final dos encontros elaboramos uma homepage, com todo o material produzido durante o projeto

Ao utilizarem instrumentos/dispositivos de potencialização como sites pessoais, conexões (logins, links dos hipertextos) construíram um mundo comum, que pode, ao mesmo tempo, ser pensado diferentemente dentro de cada um de dos participantes, devido ao rompimento das dimensões pelas Novas Tecnologias da Informação e da Comunicação. Durante as navegações, descobrirem sites de seu interesse e, a partir de seu desejo, desenvolveram atividades que Ihes foram fundamentais, tanto ao aprendizado de vocabulário como de gramática, conhecimentos gerais etc. A troca de sites entre si, demonstrava cooperação e interação. Foram estabelecidas conexões, criaram amizades e isso pode ser constatado pelo tratamento, pelo carinho, pelo respeito que havia entre os participantes.

A satisfação dos alunos ao alcançarem um objetivo mais específico, causava uma evidente mudança de subjetividade, como pode ser percebido no caso de uma aluna que, ao conseguir comunicar-se em Inglês, através do chat, após vencer momentos iniciais de insegurança, conseguiu estabelecer comunicação em inglês. O Ciberespaço, a Internet possibilitou a ela a saída de si do corpo para conquistar novos espaços.

Observou-se, principalmente, a lógicacircular na utilização dos chats, quando fomos todos emissores e receptores num tempo/ espaço indeterminado. Essa atividade foi assim avaliada por um aluno: "Eu adorei "conversar" em Inglês com outra pessoa pela Internet. É um desafio. Você tem que ler, entender, pensar numa resposta rápido e escrever tudo o que você pensou em Inglês! Além de ser um ótimo exercício para quem está aprendendo, é divertido. Eu consegui me comunicar bem e adorei o desafio de ter que dar uma resposta na hora, e escrever certo para a outra pessoa entender."

Através do chat evidencia-se o crescimento de aprendizagem da língua estrangeira, por que nesse processo colaborativo, com o fluir significativo das conversações entre os participantes, todos estão com as idéias abertas fazendo surgir trocas de visões entre as pessoas, como um verdadeiro pingue-pongue. $E$ os participantes, falando ou se preparando para falar estão, cada um a seu modo, advogando em defesa de seu próprio ponto de vista. E cada visão dessas, está baseado em alguma observação, interpretação ou generalização. A maioria concordou que o esforço de responder as mensagens em Inglês era inicialmente um desafio, mas que aos poucos se tornava natural

Nesse tipo de aula podem, ainda, ser utilizadas atividades que surjam a partir de situações do cotidiano, ou seja, um dia de muito frio e chuva, faz surgir o interesse pela busca na Internet ao "Weather forecast", resultando em pesquisa nas diferentes regiões como a Europa, o Brasil, os Estados Unidos. Em outro momento, pesquisar o horóscopo, torna as interações mais veementes, pois esse assunto fala diretamente com as emoções de cada um. Os conteúdos emergidos a partir da emoção também privilegiam a conversação e, entre outros assuntos, falávamos sobre filmes, livros, viagens, etc., que mobilizavam os alunos a navegar em busca de informações que pudessem servir de subsídio à futuras discussões.

Quanto à escrita, através da utilização do hipertexto, percebe-se ser um processo recursivo, pois os alunos liam e escreviam os e.mails utilizando dicionários, fazendo anotações ou utilizando outras fontes para encontrar padrões ou vocabulário visto anteriormente. A cibernética está presente na forma pelo qual o aluno aprende a aprender, tanto a aprendizagem do contexto quanto a do conteúdo. Isso significa que na prática o educando aprende a seguir certos passos, o conhecimento aumentando quando aumenta o aprendizado. Em relação ao multimeio, portanto, a informação é resultante da experiência do aprendizado nesses ambientes

Percebe-se a presença de sentimentos na união do virtual com o humano, uma vez que os contatos virtuais favorecem vantagens em relação à timidez. Nesse contexto, os alunos sempre acabam aprendendo algo sobre habilidades sociais através da interação, porque o senso de conectividade leva ao conhecimento um do outro, através das experiências compartilhada. Uma aluna escreveu: "Quando comecei, dois meses atrás, eu tinha vergonha de mandar uma simples mensagem a um colega em português, imagina em inglês....... agora penso que é melhor me comunicar, mesmo que eu escreva com alguns errinhos... perdi muito do receio que eu tinha". Como observadora implicada, constatei, de fato, ao final das atividades, que a maioria mostrou-se mais 
segura e apta a interagir no ambiente multimeio. Foi consenso entre os alunos, que essa forma de trabalhar desenvolveu muito seu aprendizado sobre a língua estrangeira, no caso o Inglês, e que a experiência valeu, principalmente, porque foi vivenciada, e também, porque a grande variedade do material autêntico encontrado na WWW aumentou o interesse dos alunos e os instigou a ler em Inglês, devido à velocidade (o rápido acesso a um dicionário), ao desafio presente nos temas, variedade de tópicos (que muitas vezes conduzem a informações posteriores) e aos efeitos visuais (muitas páginas apresentam gravuras ou ilustrações coloridas).

\section{Considerações finais}

O espaço projetado mostrou ser de imanência, fazendo emergir novos processos mentais e novos modos de experimentar a vida. As emergências, os produtos das interações anotadas por mim, no meu diário de bordo no desenrolar do projeto, denotaram a presença de certos padrões de interação, ou seja, a recorrência, a emoção, a perturbação foram categorias facilmente observáveis. Esses padrões permitem delinear uma avaliação positiva, além de outros aspectos que julgamos favoráveis na pesquisa, como a intensidade da manifestaçãodecondutaautônomaapresentada durante as aulas, o desempenho obtido no uso do ambiente multimeio, a participação no processo de aprendizado, a relação cooperativa observada entre os participantes e a intensidade das interações.

Os envolvidos na pesquisa se mobilizaram a aprender inglês, porque perceberam ser possível, através da utilização dos dispositivos presentes na Internet, como chats, listas de discussão, e.mail e outros, desempenhar as quatro habilidades necessárias, ou seja ouvir, ler, escrever e falar uma língua estrangeira. Ao se envolverem, participaram de um processo de aprendizado transformador, onde aprenderam sobre o aprender, sobre tecnologia e sobre eles próprios. A práxis nos mostrou, portanto, que é possível aprender Inglês através da utilização da Internet, sobretudo de modo prazeroso, além de desencadear novas possibilidades de vida, transformando, subjetivando os sujeitos autopoiéticamente, pelo desejo de criação e pela invenção.

Quanto à avaliação, esta surgiu, entre outras formas, em nível de satisfação no processo de aprendizagem, durante as aulas, quando os alunos faziam colocações sobre seu modo de pensar de maneira crítica, ao participarem das atividades produzindo seu próprio material escrito, ou participando de forma oral. Ainda, quando enviavam e.mails, cooperavam com

seus colegas, e principalmente, quando mostravam prazer em relação ao que estavam fazendo, porque suas construções eram significativas. Observei, também, que a autoestima ia sendo resgatada por parte de alguns alunos, transcendendo, pouco a pouco, e o que me dava uma particular sensação de alegria era ver a satisfação estampada em seus rostos após uma vitória, uma conquista.

Considerando o caráter auto-organizativo desse processo educacional, pode-se acreditar que somos capazes de mudar a realidade social se mudarmos as idéias, pensando conceitos ecologicamente, não como verdades, mas como ferramentas de construção. Essa nova situação de aprendizado traz a possibilidade de tornar as pessoas mais responsáveis pela sua própria construção de conhecimento, e através da autonomia e da cooperação, desenvolver a inteligência e a habilidade de interferir no meio ambiente e mudar o mesmo, se necessário.

Concluí a observação tendo, no mínimo, a certeza de que a aprendizagem ocorreu de maneira prazerosa, a partir do desejo dos alunos, pois como diz Maturana (1993), em uma entrevista concedida, "a vida não nos custa nada. A luta com o viver é que nos custa".

\section{Referências}

BATESON, Gregory. Steps to an ecology of mind. New York The University of Chicago Press, 1999.

BERGSON, Henry. Ensaio sobre os dados imediatos da consciência. Lisboa: Edições70, 1988.

BOETTCHER, Dulci Marlise. 0 uso da Internet na aprendizagem de inglês como língua estrangeira na região de Santa Cruz do Sul. Dissertação de Mestrado - UNISC, Santa Cruz do Sul, 2001.

KASTRUP, Virginia. Ainvenção de si e do mundo. Uma introdução do tempo e do coletivo no estudo da cognição. São Paulo: Papyrus, 1999.

LÉVY, Pierre. As tecnologias da inteligência: o futuro do pensamento na era da informática. São Paulo: Editora 34, 1995, e 1999, 3a reimpressão. 
1995. A árvore do conhecimento. São Paulo: Escuta,

. O que é o virtual? São Paulo: Editora 34, 1996.

1998.

Inteligência coletiva. São Paulo: Editora Loyola,

. Cibercultura. São Paulo: Editora 34, 1999 e 2000.

MATURANA, Humberto. A ontologia da realidade. Belo Horizonte:

Editora da UFMG, 1997.

Emoções e linguagem na educação e na política.

Belo Horizonte: Editora da UFMG, 1999. 